\title{
Reconsidering the ignorabimus: du Bois-Reymond and the hard problem of consciousness
}

\author{
Paolo Pecere \\ University of Roma Tre \\ Email: paolopatch@gmail.com
}

\begin{abstract}
Argument
In this paper I present an interpretation of du Bois-Reymond's thesis on the impossibility of a scientific explanation of consciousness and of its present importance. I reconsider du Bois-Reymond's speech "On the limits of natural science" (1872) in the context of nineteenth-century German philosophy and neurophysiology, pointing out connections and analogies with contemporary arguments on the "hard problem of consciousness." Du Bois-Reymond's position turns out to be grounded on an epistemological argument and characterized by a metaphysical skepticism, motivated by the unfruitful speculative tendency of contemporary German philosophy and natural science. In the final sections, I show how contemporary research can benefit from a reconsideration of this position and its context of emergence, which is a good vantage point to trace open problems in consciousness studies back to their historical development.
\end{abstract}

Keywords: Neuroscience; consciousness; materialism; mysterianism

\section{Introduction}

Research on the neural correlates of consciousness has made significant progress in the last 20 years, stimulating philosophy to respond in a number of ways. First of all, the definition of phenomena that have to be correlated to given neural structures and processes involves the use of philosophical and psychological concepts such as "awareness," "attention," "phenomenal consciousness," "access consciousness," and "self-consciousness." Many researchers consider this kind of interdisciplinary collaboration to be a healthy and promising practice in the field. ${ }^{1}$ But the philosophical debate is also characterized by a significant revival of metaphysical hypotheses, with special regard to the place of phenomenal consciousness in nature. David Chalmers, who has introduced the phrase "the hard problem of consciousness" in order to characterize the problem of explaining the relation between subjective experience and brain activity, has examined the progressive revival of a whole range of alternatives over the course of his philosophical career: first, he formulated a critique of functionalism and materialism as inadequate to explain subjective experience (and the consequent restatement of the consciousness problem); second, he reconsidered different kinds of dualism; third, since the 2000s, he examined the revival of kinds of panpsychism (or Russellian monism), and, more recently, of kinds of idealism (Chalmers 2019; see also Chalmers 1996 and 2016).

This metaphysical revival has been usually accompanied by the recognition that different hypotheses are more or less plausible and that they are not empirically separable yet. The alternatives are therefore compared by means of logical arguments, thought experiments, and metaphysical suppositions (see e.g. Papineau 2004, 21, 176-230 [in defense of materialism]).

\footnotetext{
${ }^{1}$ See the programmatic statement in (Block, Carmel et al., 2014).
} 
On this basis it is easy to pass from one theory to the other: e.g. the consideration of mental properties as intrinsic properties of matter turns materialism into panpsychism. ${ }^{2}$ This epistemic situation, to be sure, is not new in philosophy of mind since the decline of logical empiricism with its anti-metaphysics: from Herbert Feigl to David Lewis, metaphysical hypotheses concerning the mind-body problem have been regularly defended by means of new arguments rather than new empirical evidence, although there has been an expectation that future discoveries would be able to eliminate alternatives. However, philosophers have sometimes pointed out that empirical discoveries in cognitive sciences are not accompanied by any progress on the metaphysical side. ${ }^{3}$ This suspicion is also nothing new: it reminds us of the radical anti-metaphysics of the Vienna Circle and suggests that the entire development of cognitive sciences following the decline of logical empiricism has produced no substantive progress concerning the explanation of consciousness.

In this paper I propose to reconsider this conundrum starting from the scientific and philosophical context of late nineteenth-century Germany. Some scholars and philosophers have acknowledged that contemporary problems of philosophy of mind were formulated in similar terms by important scientists of the nineteenth century, including Thomas Huxley, John Tyndall, and Emil du Bois-Reymond. Neil Tennant has elaborated on this point in an excellent paper, arguing that

eminent figures in German Naturphilosophie, along with their Victorian counterparts across the Channel, had already given reasonably complete expression to several of the major themes of contemporary analytical and scientifically informed philosophy of mind. Various nineteenth-century figures championed quite explicitly hard-line versions of materialism, supervenience and rudimentary functionalism, as well as mysterianism and the explanatory gap. (Tennant 2007, 770)

These themes appeared in one of the most important intellectual controversies of late nineteenth-century Germany, the "Ignorabimus controversy" (Ignorabimusstreit), initiated by $\mathrm{du}$ Bois-Reymond's famous statement, in his lecture On the Limits of Natural Science, that "not only is consciousness inexplicable by its material conditions in the present status of science, which everyone will readily admit, but that, even according to the nature of things, it never can be explained by these conditions" (du Bois-Reymond [1872] $1886[=\mathrm{LN}], 117 / 24)^{4}-$ a conclusion that du Bois-Reymond sealed with the formula: Ignorabimus ("we will never know").

Tennant advises: "These and related works make one realize that contemporary writers are engaged in a re-play, more than a century later, of what du Bois-Reymond called a critical discussion striking all notes 'from happy praise in agreement, to the most dismissive censure"' (Tennant 2007, 747).

This assessment raises a number of issues that have not been addressed yet and that will be the object of this paper. First, which was exactly du Bois-Reymond's position in its original context? Second, why historians of philosophy of mind should take this late nineteenth-century context as particularly worthy of a reconsideration in the light of contemporary debates? Third, which insights can be gained from parallels that contemporary philosophers of mind have drawn between the two contexts?

After a brief introduction of du Bois-Reymond's argument $(\$ 2)$, I will point out that Bois-Reymond and others formulated early versions of current questions and thought experiments in a closely related scientific and metaphysical context. I will argue that there is a historical connection between nineteenth-century Germany and contemporary philosophy of mind, and

\footnotetext{
${ }^{2}$ See the discussion on this thesis, defended by Galen Strawson, in Freeman 2006.

${ }^{3}$ E.g. Daniel Dennett $(1985,3)$ detected a "fruitless pendulum swing" from one hypothesis to the other.

${ }^{4}$ I add the pagination of the English translation by J. Fitzgerald, Popular Science Monthly, 5 (1874), 17-32. I have occasionally modified this translation.
} 
that this early context provides a very good vantage point to trace open problems in consciousness studies back to their historical development ( $\$ 3$ ). Second, I will examine Bois-Reymond's philosophical views, arguing that these cannot be assimilated, as it has been suggested, to contemporary philosophical views such as materialism or mysterianism $(\$ 4)$. Third, I will focus on the analogies and differences between du Bois-Reymond's argument and the arguments of David Chalmers $(\$ 5)$. My conclusion, corroborated by more examples $(\$ 6)$, will be that du BoisReymond's Ignorabimus deserves to be reconsidered as an original position on the problem of consciousness and suggests a historically motivated critique of current tolerance towards metaphysics in philosophy of mind.

2. Du Bois-Reymond's lecture "On the Limits of Natural Science" (Über die Grenzen des Naturerkennens) was delivered on August 14, 1872, at the meeting of the Gesellschaft Deutscher Naturforscher und Ärzte, the most important interdisciplinary scientific society among speakers of German. At that time du Bois-Reymond was a well-known and highly respected physiologist. His Investigations on Animal Electricity (1848-60) had provided a widely debated foundation of electrophysiology and an exemplary application of physicalism in the life sciences. Though he was an atheist and theorized the possibility of a physico-chemical explanation of life, du Bois-Reymond had not intervened in the "materialism controversy" (Materialismusstreit) that had raged in the German speaking countries since the 1840s, dividing prominent physiologists and philosophers on both sides of a harsh cultural, religious, and political divide. In 1872 he served as the Rector of the University of Berlin and the President of the Berlin Academy of Sciences, making him a major spokesman for science in the political and cultural context of the newly founded German Empire. His lecture started with a celebration of the progress made in natural science and, in determining its limits, did not intend to diminish science with respect to faith or philosophy. Du Bois-Reymond aimed rather at establishing the legitimacy of natural science and resolving previous metaphysical controversies.

$\mathrm{Du}$ Bois-Reymond's lecture begins with a definition of natural science as the "the resolution of natural processes into the mechanics of atoms." By the use of mathematical formulations and the application of the laws of conservation of energy and quantity of matter "there remains in these changes themselves nothing further that needs explanation" (LN, 106/17; emphasis added). In order to examine the idea of the best possible understanding of nature, to be expressed as "one mathematical formula," du Bois-Reymond borrows from Laplace (and Leibniz) the hypothesis of a Mind (Geist) knowing all the momenta and positions of all particles in the universe. This Mind would be able to reduce every change in the world to a mathematical "universal formula" [Weltformel] of linked simultaneous differential equations (LN, 107/18). Still, this ideal knower would encounter a first limit to its explanatory power: the understanding of the "essence" of atoms and forces. The attempt to reduce the continuum of matter to the causes of movements in the smallest elements of it leads to two unsatisfactory alternatives: extended impenetrable atoms, which would still be divisible and hence not elementary, or the "middle points of central forces," which would be without extension and thus "a chimera" (ein Unding) (LN, 112/21). Hence our ideal of a perfect knowledge that traces things to their first causes in atoms and forces leads to "contradictions," and only provides a "substitute for an explanation." According to du BoisReymond, this "is not knowledge at all" (LN, 111/20-1).

Du Bois-Reymond's argument resembles one made by Kant. ${ }^{5}$ His notion of "limit" (Grenze) also echoes Kant's (1900-[1783], 352): "limits" (Grenzen), contrary to "boundaries" (Schranken), do not presuppose a space outside a location, but are merely negations of the "absolute completeness" of a magnitude. In du Bois-Reymond's case (as we will see in detail): we never meet the limits in the process of scientific investigation and there is no unknowable scientific truth that lies beyond

\footnotetext{
${ }^{5}$ The Kantian sources may be the second "Antinomy of pure reason" of the first Critique or the account of atoms and pointlike monads in the Metaphysical Foundations of Natural Science (1786).
} 
the limits of natural science. This means that the value of the atomistic representation in our "physico-mathematical study" is intact, as long as we "do not cross the limits of the demands that it is intended to meet" (LN, 111/21). In fact, we can predict the whole evolution of the universe starting from original nebulae to the infinite future states of matter, including the transition from inorganic to organic matter (LN, 114-6/22-4).

$\mathrm{Du}$ Bois-Reymond introduces the explanation of consciousness by its material conditions as a further point where the "thread of intelligence" is broken and we face a "chasm $[\mathrm{Kluft}]$ across which is no bridge." His analysis focuses on "the first grade of consciousness, i.e. sensation" conceived as a basic feature of all conscious "mental processes" (LN, 117-8/24-25). We can envisage the possibility of knowing every detail of the material processes accompanying pleasure, pain and all sorts of intellectual operations, but still the mental operations themselves would remain "perfectly unintelligible" in their phenomenal aspect:

What conceivable connection subsists between definite movements of definite atoms in my brain, on the one hand, and on the other hand such (for me) primordial, indefinable, undeniable facts as these: 'I feel pain, pleasure; I experience a sweet taste, or smell a rose, or hear an organ, or see something red,' and the immediately consequent certainty, 'Therefore I exist?' ... It is utterly inconceivable how consciousness should result from their joint action. $(\mathrm{LN}, 123 / 28)$

This argument does not merely refer to a temporary ignorance, but notably can be applied to any future development in our understanding of the natural world (see below $\$ 4$ ). Hence the scientist "must resign himself once and for all to the far more difficult confession: 'Ignorabimus?" (LN, 130/32).

In the debate on his speech, du Bois-Reymond was accused of giving a reductive picture of the prospects of science and thus favoring metaphysical speculation and religious reaction. ${ }^{6}$ Surprised by these reactions, he protested that he had just repeated well-known philosophical views - "stale beer," as he called them (du Bois-Reymond 1886, 381-382). Indeed he mentioned, among other sources, Leibniz, Locke, La Mettrie, and Tyndall (LN, 138-9, n. 29, 33; Finkelstein 2013, 282-284). Therefore, before we examine du Bois-Reymond's argument in more detail, we have to understand why his peculiar formulation of the problem has been taken as model by some contemporary philosophers of mind and provides indeed a vantage point to reconsider ongoing debates.

3. Du Bois-Reymond's argument is epistemological: natural science works by connecting facts, but the connection of these two kinds of facts, movements of atoms in the brain and private sensations, is inconceivable. This does not involve any ontological position, although du BoisReymond sympathizes with a materialistic one:

Whether we shall ever understand mental phenomena from their material conditions is a very different question from that other, whether these phenomena are the product of material conditions. The former question might be decided in the negative without in the least affecting the latter, to say nothing of negating it. (LN, 127/31)

Du Bois-Reymond's "sensation" (as shown by the quotation above in $₫ 2$ ) includes any subjective and qualitative content of consciousness, from feelings to sensory perceptions. Given this exception, du Bois-Reymond (1886, 396-397) believes that any kind of mental content - including drives, memory and "rational thought" - can be explained in terms of "brain mechanisms" that were developed in natural evolution. Du Bois-Reymond indeed subscribes to a kind of supervenience of the mental on the physical, claiming that physical phenomena "are always, and hence

${ }^{6}$ On the Ignorabimus controversy, see Bayertz, Gerhard and Jaeschke 2007; Finkelstein 2013, 269-280; Beiser 2014, 97-132. 
necessarily, simultaneous with mental phenomena" (LN, 121/27). ${ }^{7}$ However this supervenience does not help with the explanation of the emergence of consciousness from physical processes. In order to illustrate the problem, du Bois-Reymond introduces the case of a "dreamless sleeper," whose brain processes would be perfectly known and predictable insofar as he does not start dreaming and, thereby, having conscious experiences:

A brain that should, from one cause or another, be unconscious - for instance, one that should sleep without dreaming - would, had we astronomical [i.e. perfect physical] knowledge of it, hold no secret .... The dreamless sleeper is comprehensible to us, like the universe previous to consciousness. But, as, on the first awakening of consciousness, the world became doubly incomprehensible, so too is it with the sleeper, at the first appearance of a faint image in dreaming. (LN, 124/29)

This situation is generalized to the entire world as it is conceived by Laplace's Mind:

In a world of mobile atoms, the cerebral atoms are in motion indeed, but it is a dumb show. This Mind views their hosts, and sees them crossing each other's course, but does not understand their pantomime; they think not for him, and hence, as we have already seen, the world of this Mind is still meaningless. (LN, 125/29)

Similar ideas were advanced in the context of the materialism controversy. In his celebrated History of Materialism and Critique of its Present Importance (1866), Friedrich Lange maintained that the "subjective state" of the perceiver corresponds to a "limit to materialism" and of natural science in general, because it is "impossible" to determine "the relation of the subjective phenomenon of sensation to the [simultaneous] objectively observed nervous process" (Lange 1866, 456). ${ }^{8}$

$\mathrm{Du}$ Bois-Reymond may have been directly influenced by this formulation. Lange, in turn, in the second edition of the book would praise du Bois-Reymond's lecture and present the 'twin world' thought experiment as follows:

We suppose two worlds, both occupied by men and their doings, with the same course of history, with the same modes of expression by gesture, the same sounds of voice for him who could hear them, i.e., not simply conduct their vibrations through the auditory nerve to the brain, but be conscious of them to himself. The two worlds are therefore to be absolutely alike, with only this difference, that in the one the whole mechanism runs down like that of an automaton, without anything being felt or thought, whilst the other is just our world; then the formula for these two worlds would be entirely the same. To the eye of exact research, they would be indistinguishable. (Lange 1873 vol. $5,2^{\text {nd }}$ ed., 56)

Some contemporary philosophers have pointed out the analogy between du Bois-Reymond's problem of sensation and the "hard problem of consciousness" (see $\$ 4$ ). David Chalmers, in his formulation of this problem, also argues that all sensory processing and elaboration of information be (functionally) explained, but even if we solve all these problems the "hard problem" would be still unanswered: "why is all this processing accompanied by an experienced inner life?" (Chalmers 1996, xii; 47). This "explanatory gap" (to use the phrase coined by Joseph Levine) corresponds, in this different context, to du Bois-Reymonds's "chasm." The "dreamless sleeper" and "twin worlds" thought experiments also resemble those introduced in philosophy one

\footnotetext{
${ }^{7}$ On this and similar views of supervenience in the late nineteenth century, see Tennant 2004, 750-753.

${ }^{8}$ Where passages correspond, I quote (with occasional modifications) from the translation of the $3^{\text {rd }}$ edition of Thomas 1925.
} 
century later in order to illustrate the "absent qualia" problem by means of "imitation men," "zombies," "zombie worlds" and the like (see Chalmers 1996, 94-99, 369 n. 1).

These analogies may depend on the historical connection between the Ignorabimus controversy and today's debate on consciousness in cognitive sciences. The controversy belonged to the intellectual background of philosophers such as Rudolf Carnap and Herbert Feigl, who would play a prominent role in the transmission of topics of European philosophy in the United States. Carnap's conception of the mind-body problem as a "pseudoproblem," as well as Feigl's later revival of the problem (who would contribute to the fresh start of philosophy of mind in the 1950s), both belong to this posterity. And these, in turn, are the philosophical roots of contemporary debates on brain and consciousness (see below $\$ 5$ ).

But this transmission would not imply that the Ignorabimus controversy is the origin of the hard problem of consciousness. To be sure, similar ideas had been already formulated since the seventeenth century, because they ultimately depend on the crisis of Aristotelian hylemorphism and the breakthrough of mechanistic philosophy with its new concept of matter. Notably Descartes introduced the idea of studying the body as "a statue or machine" (Descartes [1662] 1964-74, XI:120), while at the same time excluding consciousness from the essential properties of matter. Leibniz had devised a "duplicate" thought experiment and remarked that "perception, and anything that depends on it, cannot be explained in terms of mechanistic causation" (Leibniz [1714] 1932, 609; compare LN, 127-128/31). ${ }^{9}$ In fact, the philosophical concept of the zombie was originally conceived against exactly the same Cartesian conceptual background, as a tool to discuss identity theory (Kirk, Squires 1974, 135-52), and it is common among contemporary philosophers and neuroscientists to set the historical and conceptual origins of the problem of consciousness for better or for worse - in Cartesian philosophy.

But a number of reasons suggest that a reconsideration of du Bois-Reymond's argument, and its original context, offers a better vantage point on some crucial aspects of contemporary philosophy than these modern antecedents. The difference is made by background elements that significantly modified the way philosophers and scientists of the mid-nineteenth century investigated the connection of brain and consciousness.

First, du Bois-Reymond's physicalist physiology rests on the formulation of the law of the conservation of energy. While Helmholtz ([1847] 1882, 13) had connected the new principle to the issue of free will, du Bois-Reymond, who had previously made the same connection ([1848] 1887, 9-10), applied the principle in the 1872 lecture to the problem of mental processes in general:

Motion can only produce motion, or be converted back into potential energy. Potential energy can only produce motion, maintain static equilibrium, or exert pressure or traction. The sum of energy, however, remains the same. Beyond this law nothing can go in the physical world, nor can any thing fall short of it; the mechanical cause passes completely into the mechanical effect. Hence the mental phenomena, which in the brain appear in company with material phenomena, are, so far as our understanding is concerned, void of sufficient basis. They lie beyond the law of causality, and hence are unintelligible, like a perpetuum mobile. (LN, 122-123/28)

Helmholtz' principle disposed of the spiritual dimension of the conservation of force in Leibnizian physics (du Bois-Reymond 1886, 399-400), and connected for the first time mechanical, thermal and electrical phenomena to the physiological study of cognitive processes. This breakthrough was the basis for the definition of the "causal closure" of the physical world, which is a typical characteristic of contemporary consciousness studies (Papineau 2004, Appendix; Tye 2016).

\footnotetext{
${ }^{9}$ In the manuscript essay, "Anima quimodo agit in corpus" (circa 1677-78), Leibniz made the following remark: "If minds were eliminated leaving the laws of nature (which would be impossible), the same thing would happen as if there were minds: books would even be written and read by human machines, though they would understand nothing (Leibniz 1923-, 6(4):1367).
} 
A second element of du Bois-Reymond's background that we have to take into consideration is the rise of neuroscience as a mathematical and experimental discipline, which was centered in nineteenth-century German speaking countries. Successive groundbreaking developments that established neuroscience as we know it include the investigation of reflex action by Johannes Müller (who granted priority to Marshall Hall's almost contemporary research); the first development of cell theory by Theodor Schwann, Robert Remak, and Rudolph Virchow; the quantitative study of nerve currents by Helmholtz and du Bois-Reymond himself; the discovery of neural inhibition by Ivan Sechenov; and the psychophysical investigations on the relations of stimulus and intensity of sensation by Wilhelm Weber and Gustav Fechner. Except for psychophysics all these advancements were made in the school of Johannes Müller, the teacher and Doktorvater of du Bois-Reymond in Berlin. Pioneering experiments on electrical stimulation of the brain cortex by Gustav Frisch and Eduard Hitzig were conducted in the same intellectual context.

$\mathrm{Du}$ Bois-Reymond makes a number of references to this new scientific context in his 1872 lecture. He quotes Müller's theory of specific "sense-substances" as an important attempt to explain the "quality" of the otherwise "senseless substratum" of our world (LN, 109-110/22-23). He also quotes Fechner's psychophysical studies and Franciscus Donder's "measurement of the duration of simpler mental operations" - a result that depended on Helmholtz' groundbreaking measurement of the speed of neural transmission in 1850 - as examples of the new "direct insight in the material conditions of mental phenomena" (LN, 122/27). It is usually recognized today that these discoveries opened the way to the neuroscientific investigation of sensory perception, which plays a prominent role in consciousness studies (see e.g. Kandel 2012, 202-203).

A third crucial point is the naturalistic intellectual background introduced by Darwin's theories. Du Bois-Reymond devotes a long passage to highlight the epochal turn determined by the theory of natural selection which, joined to the theory of natural descent, "forces upon him [the natural scientist] the theory that the soul came into being as the result, gradually attained, of certain material combinations, and that probably, like other heritable endowments that are of use to the individual in the struggle for life, it has risen and perfected itself up to its present state through a countless series of generations" (LN, 127/30).

Du Bois-Reymond was the first Darwinist in Germany: he wrote a number of essays on the epistemological meaning of the theory of natural selection (Finkelstein 2013, 233-53) and connected his own views to a naturalistic tradition encompassing Democritus, Epicurus, Lucretius, La Mettrie and Darwin (du Bois-Reymond 1886, 188, 196).

A fourth contextual element that plays a major role for our purposes is the debate on the metaphysical interpretation of natural science. Du Bois-Reymond's skepticism was directed mainly against two alternatives: materialism and idealism. On the one hand, materialism was presented by its adherents as the philosophical view imposed by empirical natural sciences (Gregory 1977), while many replied that the two have to be separated, e.g. Helmholtz $(1867,796)$ had argued that "materialism is an equally ungrounded metaphysical speculation or hypothesis as spiritualism," and du Bois-Reymond would accept this view (see $\$ 4$ ).

Idealist or vitalist metaphysics was also a major source of inspiration for German physiology (Clarke and Jacyna 1987; Hagner 2008). Müller himself had defended the existence of a metaphysical life force and developed his theory of the sense-energies in the wake of early nineteenthcentury Naturphilosophie (Hagner, Wahrig-Schmidt 1992). This legacy of Müller was a major critical objective of the physicalist students of Müller. But speculative approaches were still common. An important example is Fechner, also mentioned by du Bois-Reymond in his reappraisal of the hypothesis that mind and matter "may be after all only one" (LN, 127/30-31). ${ }^{10}$ Fechner was attempting to corroborate his "identity theory" - a metaphysical monism that he named after

\footnotetext{
${ }^{10}$ In a footnote $(1886,139$, n. 36$)$ du Bois-Reymond presents Fechner's view as an interpretation of Leibniz' pre-established harmony, conceived as a dualistic theory. Du Bois-Reymond - correctly - points out that Leibniz himself contemplated a monistic hypothesis.
} 
Schelling (Heidelberger 2004, 112) - with the empirical and mathematical investigation of psychophysical parallelism, thus challenging the divide between science and metaphysics. It was precisely this kind of natural science that du Bois-Reymond, Helmholtz, and other members of the Berlin Physical Society had wanted to eradicate, as contrary to the methods of physics and chemistry, hence rejecting an important background element of Müller's physiology (Cranefield 1957; Finkelstein 2013: 64).

On the whole, I think that these elements - conservation of energy, rise of experimental neuroscience, Darwinian naturalism, critical debate on materialism and speculative revivals point to an interesting homogeneity between the late nineteenth-century German scientificphilosophical culture and today's cognitive sciences. This suggests that some features of the Ignorabimus debate may still be of interest from today's perspective, as it has been argued by some philosophers and scholars. ${ }^{11}$ But in order to take stock of these proposals we have to focus first on the question: what exactly was du Bois-Reymond's position?

4. Du Bois-Reymond's thesis found a variety of interpretations. The idea that there is a limit of natural science was alternatively praised because it corroborated the broadly Kantian view that materialism is a "maxim of natural investigation" rather than a metaphysical truth (Friedrich Lange), revealed the need for a fundamental metaphysics (Nicolai Hartmann), or necessitated a distinction between the principles of natural and moral sciences (Wilhelm Dilthey). Christian apologists and even occultists like Rudolf Steiner welcomed the Ignorabimus as a confession of the weakness of science. On the other hand, du Bois-Reymond was blamed because his lecture encouraged obscurantism (Ernst Haeckel), or because it was grounded on a restricted mechanistic view of scientific knowledge, thus denying the possibility that future discoveries might abolish its limits (William Preyer, Wilhelm Ostwald) and prove that consciousness was a property of matter (Carl von Nägeli). Although he restated his view in The Seven World Riddles, du Bois-Reymond did not manage to establish a standard interpretation of his ideas, the debate over which extended into the twentieth century. ${ }^{12}$

Things are even more confused in contemporary philosophy. Michael Tye $(1999,707)$ has assimilated Colin McGinn's “mysterianism” to du Bois-Reymond's Ignorabimus. McGinn's thesis is that, when we face the problem of consciousness, "we are cut off by our very cognitive constitution from achieving a conception of that natural property of the brain (or of consciousness) that accounts for the psychophysical link" (McGinn 1989, 350). It can be argued that du BoisReymond's view was different, but in order to understand this point we must consider the origins of McGinn's claim. Block $(1995,231)$, Tennant $(2007,750)$, and others have pointed out that a precedent source for the idea of "cognitive closure" was Thomas Huxley in his well-known Lessons in Elementary Physiology. Huxley did not deny the material conditions of consciousness, but he doubted the possibility of explaining "how" mental states emerge from brain activity:

We class sensation along with emotions, and volitions, and thoughts, under the common head of states of consciousness. But what consciousness is, we know not; and how it is that anything

\footnotetext{
${ }^{11}$ Tye (1999) has suggested an analogy with Colin McGinn's "mysterianism," which has been discussed by Tennant in the above quoted paper (Tennant 2007). I examine this interpretation below. On the influence of the Ignorabimus on Wittgenstein and contemporary philosophy of mind, see respectively the papers by Kurt Bayertz and Michael Pauen in Bayertz, Gerhard, and Jaeschke (2007, 150-204). David Chalmers has recently pointed out the groundbreaking importance of du Bois-Reymond's thesis that consciousness, contrary to behavior, cannot be explained. According to Chalmers, du BoisReymond, John Tyndall, and other nineteenth-century scientists were possibly the first to isolate the problem that neuroscience has started to address only in the late twentieth century (Chalmers and Pecere 2019).

${ }^{12}$ The relevant passages by Hartmann, Lange, von Nägeli, Dilthey, and Ostwald are collected in Bayertz, Gerhard, Jaeschke (2012). The editors of this collection also outline Preyer's and Steiner's interpretations in the Introduction (xi and xxxxi). References to the original texts are included in this collection. Haeckel's attack is in Haeckel (1874, xii ff.): Du BoisReymond directly replied to Haeckel and von Nägeli in The Seven World-Riddles, dismissing their conception of sensitive matter as a metaphysical delusion (see below $₫ 5$ ).
} 
so remarkable as a state of consciousness comes about as the result of irritating nervous tissue, is just as unaccountable as the appearance of the Djinn when Aladdin rubbed his lamp, or as any other ultimate fact of nature. (Huxley 1866, 193)

In the second edition (1872) Huxley endorsed the supervenience thesis, but he declared that the connection of material and conscious processes surpasses "our cognitive powers" (Huxley 1872, 300). This thesis has already been spelled out by Tyndall in his address on "The Scope and Limit of Scientific Materialism" of August 19, 1868, published in Fragments of Science (1871). Here Tyndall pointed out the "extreme probability" of the supervenience of consciousness on physical states of the brain, and commented:

The passage from the physics of the brain to the corresponding facts of consciousness is unthinkable. Granted that a definite thought and a definite molecular action in the brain occur simultaneously, we do not possess the intellectual organ, nor apparently any rudiment of the organ, which would enable us to pass, by a process of reasoning, from one to the other. They appear together, but we do not know why. (Tyndall 1871, 119-120; emphasis added) ${ }^{13}$

This idea of cognitive limitation was a development of Locke's thesis that reason can conceive the hypothesis of thinking matter, but due to its weakness could never determine anyone "for or against the Soul's Materiality" (Locke [1689] 1975, IV.iii.6, 531-3). Huxley (1871, 27983) quoted Locke as a model for his naturalist and yet agnostic, non-materialist view. Tyndall $(1871,120-1)$ defended the materialist version: he stressed that materialism had to grant the epistemic "chasm" between physics and consciousness, while not excluding that a future evolution might lead to the development of "new intellectual organs" and to the solution of the problem.

McGinn (1989, 349, 351-2) also quoted Huxley and Locke as sources for his idea of cognitive closure, arguing that "the senses are geared to representing a spatial world," but "we cannot link consciousness to the brain in virtue of spatial properties of the brain," hence the mystery remains (357). His view that the brain-consciousness link eludes the conditions of knowledge does not mean that it is not real: thus he qualified it as a noumenal reality in the Kantian sense (358).

$\mathrm{Du}$ Bois-Reymond was certainly familiar with the positions of the Victorian scientists and of their modern British antecedents, and he was sympathetic towards empiricism and psychology (LN, 138-9, n. 29). Nevertheless, du Bois-Reymond differs from these antecedents for a peculiar twist of his argument: he did not explain the problem of consciousness with an empirical limitation or a peculiar arrangement of the cognitive powers. He considered it rather as a consequence of how scientific inference works, without venturing into further explanations in terms of the cognitive apparatus. The fiction of the omniscient "Mind," for which Cassirer $(1956,3)$ credited du Bois-Reymond as a prominent interpreter of mechanical determinism, sets the epistemological stage for his argument. As du Bois-Reymond puts it in the above quoted passage, "motions only produce motions" and thus the connection of motion and consciousness lies "beyond the law of causality" (he took for granted that causality was only valid if applied to physical connections). The problem - as he rephrased it later - was "to explain consciousness ... in mechanical terms" (du Bois-Reymond 1886, 381).

$\mathrm{Du}$ Bois-Reymond's focus on scientific method rather than psychology characterized his peculiar view of the problem with respect to Huxley's and Tyndall's almost identical arguments. This epistemological nuance may depend on the way the German neo-Kantian tradition were elaborating the ideas of British empiricism: du Bois-Reymond was acquainted with the idea of an "organization" of the human mind, which had been adopted by many physiologists and philosophers for their interpretation of Kant's a priori conditions of experience. This concept was often characterized in psychological terms (e.g. by Jakob Fries and Mathias Schleiden), but

\footnotetext{
${ }^{13}$ Both Güzeldere $(1997,48)$ and Tennant $(2007,753)$ cite this passage, without addressing the issue of precedence.
} 
Helmholtz and Lange, with whom du Bois-Reymond had a close intellectual relation, argued that epistemological principles were a priori and not reducible to empirical data (see Pecere 2018).

From today's point of view, du Bois-Reymond's position turns out to be different from McGinn's more "Lockean" position. His reasoning rather resembles the "Structure and Dynamics Argument", which has been formulated by David Chalmers in order to emphasize the limits of standard scientific accounts of the mind. According to Chalmers, the "microphysical description" of the world is constituted by structural elements (a "distribution of particles, fields and waves ... characterized by their spatiotemporal properties, and properties such as mass, charge, and quantum wavefunction state") and dynamical principles, determining the evolution of properties in time (Chalmers 2002, 258). Chalmers summarizes his premises as follows:

First: Physical descriptions of the world characterize the world in terms of structure and dynamics. Second: From truths about structure and dynamics, one can deduce only further truths about structure and dynamics. And third: Truths about consciousness are not truths about structure and dynamics. (Ibid.)

In du Bois-Reymond's argument, the structural (spatiotemporal) and dynamical (law of causality, principles of classical mechanics etc.) elements of the description are easily recognized. $\mathrm{Du}$ Bois-Reymond also maintained that the "physical-mathematical method" belongs to any future scientific theory with its "new forces" (du Bois-Reymond [1848] 1887, 9-10), that is, he believed that any new theory of natural science would preserve structural-dynamical features (cf. Chalmers 2002, 259). On the whole, if we replace Chalmers' "truths" with du BoisReymond's "facts" (as facts correspond to truths), the arguments turn out to be logically identical.

This is interesting for the understanding of the historical distance between the two, because the conclusions that du Bois-Reymond and Chalmers draw from their arguments are quite different. Chalmers' aim is to exclude any kind of materialist account of consciousness, including the positions of those materialists who allow that there is an "epistemic gap". He lists three alternatives to materialism: dualistic interactionism, epiphenomenalism, and Russellian monism. For the purpose of characterizing du Bois-Reymond's position, it is interesting to examine how he also considered different metaphysical alternatives - partly coincident with Chalmers' - but rejected them all.

First of all, du Bois-Reymond rejected traditional substance dualism (which includes Cartesian interactionism). The metaphysical solutions to the mind-body problem elaborated by modern philosophers such as Descartes, Malebranche, and Leibniz were "discredited," because they were grounded on a "dualistic principle" of "semi-theological origin," i.e. the position of the "spiritual substance," which was inconceivable from the standpoint of empirical science (LN, 119/26). Second, he admitted that consciousness defined a specific class of facts and corresponded to a kind of activity (whether or not free will exists): hence, he was no epiphenomenalist either (du Bois-Reymond 1886, 399-401, 410-411).

On the other hand, as we have seen, du Bois-Reymond granted the supervenience of the mind on "material conditions" and sympathized with self-declared materialists who admitted the problem of consciousness (such as Tyndall). From this standpoint he rehearsed Leibniz' hypothesis of a physical "duplicate" of Caesar and concluded that with the existence of this Doppelgänger Caesar "would ... be restored mentally as well as bodily" (LN, 128/31). Hence he excluded the existence of non-material ontological ingredients of consciousness. In the immediately following paragraph du Bois-Reymond defended Karl Vogt's simile of thought and urine - that is, the very spark that ignited the materialism controversy:

Vogt's expression [is not] worthy of blame on the ground that it represents mental activity as being the result of material conditions in the brain. Its faultiness lies in this, that it 
leaves the impression on the mind that the soul's activity is in its own nature as intelligible from the structure of the brain, as is the secretion from the structure of a gland. (LN, 128-9/31-32)

This defense of Vogt, made by the prominent physiologist after almost 30 years, may indicate that German materialism of the 1840s was ontologically right after all, although unaware of its epistemological limits. Thus Du Bois-Reymond would be, as argued by Tennant $(2007,748)$, a "non-reductive materialist." 14 Nevertheless, du Bois-Reymond never did say that his scientific outlook endorsed ontological materialism. This was not the mere downplaying of an opinion that did not please the political authorities - at least if we take seriously his lecture on the limits of natural science - for du Bois-Reymond had good reason to reject materialism: the ignorance of "the nature of matter and force" was precisely one of the limits of natural science. To recognize that consciousness has material conditions, without knowing the nature of matter, does not involve a metaphysical position concerning the nature of consciousness. Again, this was a sensible point in the context of German natural science: from Leibniz to Kant, from Schelling to Fechner, there was a long and persisting tradition of reducing material particles to monads and/or to forces. In his lecture du Bois-Reymond (LN, 106/17-18) explicitly adopted a modified version of Kant's foundation of natural science in the Metaphysical Foundations of Natural Science (1786) by attributing "apodictic certainty" to the "propositions of mechanics." Hence he was arguably influenced by Kant's dynamical theory of matter, which is also expounded in this work. This theory rejected atomism and tried to prove (by allegedly a priori propositions) that particles of matter result from the action of fundamental moving forces. Nonetheless, the metaphysical essence of these forces was unknowable. This crucial aspect of Kant's natural philosophy had been elaborated as an alternative to both monadology and materialism, hence it provided a model for the rejection of metaphysical hypotheses in $19^{\text {th }}$ century natural science (Kant 1786, 523-525, 533; see Friedman 2013: chap. 2; Pecere 2016).

For the same reason, du Bois-Reymond could not endorse Fechner's (and Haeckel's) thesis that matter might have intrinsic conscious properties (reprised by Russellian monism). He denied the scientific value of hypotheses endorsed by Fechner, such as plant- or "WorldSouls", because there was no empirical connection between those entities and the neural correlates of consciousness. Moreover to attribute consciousness to single parts of matter "as so many monads" would not "assist us in understanding the unitary consciousness of the individual" (LN, 123/28). ${ }^{15}$ He granted that to know the nature of matter and force would provide an understanding of "how the underlying substance senses, desires and thinks," but since we couldn't cross the limits of scientific knowledge he concluded that it was "idle" to dwell on the hypothesis (LN, 129/32).

To be sure, du Bois-Reymond believed that monism was "the easiest solution to the problem" of consciousness. He also admitted the existence of mental facts and rejected any metaphysical determination of the latter, so Kantian philosophy might have appeared as a congenial solution for him. In fact du Bois-Reymond shared a number of views with Kantianism. Kant had already described the contents of cognition (excluded subjective feelings and the will) in structuraldynamical terms (Kant 1787, 66-67) and we have seen that he adopted Kant's epistemological foundation of mathematical physics as a model. Moreover, Kant had already suggested that "that same Something that grounds outer appearances ... could also at the same time be the subject of thoughts" (Kant 1781, 358). Given his criticism of alternative hypotheses, du Bois-Reymond might have liked this kind of dual-aspect monism with no determination of the noumenal substance,

\footnotetext{
${ }^{14}$ After all, du Bois-Reymond once described his view as similar to La Mettrie's $(1886,198)$.

${ }^{15}$ This passage shows that du Bois-Reymond was well aware of what is called the "combination problem" of panpsychism (see Chalmers 2002, 266). In fact, this problem had been already raised since (at least) the debates on Spinozism in eighteenthcentury France.
} 
which was a well-known option in German philosophy of his time. ${ }^{16}$ Unsurprisingly Lange, who defended such view, presented du Bois-Reymond as a Kantian in his defense of the Ignorabimus included in the second edition of the History of Materialism (Lange 1875, 478-492).

In The Seven World-Riddles (1886, 382), however, du Bois-Reymond explicitly rejected Lange's thesis that the Ignorabimus was a Kantian conclusion. The problem with Kant's philosophy was the "exoteric character" that it had impressed upon academic philosophy. This in turn had encouraged estrangement, if not hostility, of philosophy and natural science. Du BoisReymond most likely was thinking of the way Kant's a priori knowledge and transcendental idealism had been developed into non-empirical (and often scientifically uninformed) speculations in German idealism. Helmholtz $(1884$ vol.1, 122) had similarly lamented the "schism" between philosophy and sciences as an unfortunate legacy of German idealism, but esteemed Kant because his philosophy still "rested on exactly the same ground as the physical sciences." By contrast, du Bois-Reymond dismissed Kant outright.

$\mathrm{Du}$ Bois-Reymond's rejection of philosophical commitments can be better understood by considering a feature of the 1872 lecture. Addressing his audience of scientists, he described how the "natural scientist" had to behave with respect to various philosophical hypotheses. He declared that, while he had presented "to scientists" well-known philosophical views, he had "hoped only that the novelty of my method of proof might stimulate interest" (du Bois-Reymond 1886, 382; emphasis added). On the whole, we can conclude that du Bois-Reymond wanted to defend an epistemological position, founded on the principles of scientific investigation, and remained uncommitted towards materialism, idealism and other forms of metaphysics or a priori philosophy.

5. Having analyzed du Bois-Reymond's view, I can now return to the comparison between his anti-metaphysical conclusions and the more liberal approach concerning possible solutions to the problem of consciousness, which I introduced with the example of Chalmers and his structural-dynamical argument. In The Conscious Mind, Chalmers argues that empirical correlations are insufficient to deal with consciousness, since the latter naturally supervenes on physical properties, but does not logically supervene on physical properties (i.e. it is logically possible to think of those correlates without consciousness attached). This is the reason why even "Laplace's demon" would not be able to provide a "reductive explanation" of consciousness, such as the materialist explanation (Chalmers 1996, 36, 47-48). Chalmers bases his argument against materialism on the following premises:

1. Conscious experience exists.

2. Conscious experience is not logically supervenient on the physical.

3. If there are phenomena that are not logically supervenient on the physical facts, then materialism is false.

4. The physical domain is causally closed (Chalmers 1996, 161).

The first three premises imply the falsity of materialism, while the fourth requires that consciousness "arises from the physical according to some laws of nature, but is not itself physical," which is the core of Chalmers' own proposal in this book ("naturalistic dualism"). The only plausible alternative is what Chalmers ironically calls "Don't have a clue materialism," holding that consciousness has to be physical "because materialism must be true," but the fact itself is mysterious. This turns out to be an unstable thesis, which "presumably must eventually reduce to some more specific view" (162).

\footnotetext{
${ }^{16}$ In a letter to Friedrich Lange, Hans Vahinger argued that the alternative to merely empirical parallelism was "the wider Spinozian hypothesis, which says that whatever appears to us to be an external material event, is - for us - inwardly a sensation ... this latter opinion, which after Kant has been advocated by Fechner, Zöllner, Wundt, Bain, and others, and which is also your view, seems to me to be the only possible consequence of the Law of the Conservation of Energy" (in Lange 1968, 358).
} 
Now, du Bois-Reymond would accept all these premises (including "natural supervenience") but then, as we have seen, he would not endorse materialism nor any non-physical hypothesis, leaving open the whole issue concerning the essence of matter and mind. Thus, while Chalmers considers the limits of materialist explanations as a good reason to take into serious consideration the metaphysical (or non-standard scientific) alternatives, du Bois-Reymond is happy with the supervenience and takes the whole investigation of alternative possibilities - based on counterfactual analogies and no additional fact - as an idle speculation, leading to no epistemic gain. The same could be said regarding the difference between du Bois-Reymond's skeptical stance and the revival of metaphysics supported by other contemporary philosophers. Du BoisReymond is convinced that to grant even a minimal credit to metaphysical hypotheses would entirely destroy the domain of science, whereas completely abstaining from them does no epistemic harm.

But the mere argumentative analysis does not explain this divergence of views. The fact that du Bois-Reymond felt it necessary to devote several pages - in fact, almost the totality - of his account of the consciousness problem to the metaphysical alternatives shows that he was acutely aware of their significance. This was a function of his scientific context. We have seen that the whole physicalist movement in Berlin originated in an attempt to banish the speculations of Naturphilosophie from natural science. At the same time, du Bois-Reymond and Helmholtz wanted to divorce science from all metaphysical speculations, materialism included. Although this anti-metaphysical position had a growing number of followers among German scientists and philosophers, materialism and spiritualism were still quite common, and some critics viewed them as theoretically interconnected. Friedrich Lange - whom, as we have seen, strongly supported the physicalist view - endorsed the idea that materialism intrinsically involves a tendency to "leave its own sphere" and collapse into ungrounded metaphysical hypotheses such as Leibniz' monadology, i.e. materialism and spiritualism tend to conflate. This tendency manifests itself as soon as the materialist tries to establish an explanation of consciousness, since this inevitably involves attaching consciousness to matter, leading to a strikingly speculative and scientifically ungrounded worldview (Lange 1866, 28; cf. 48, 214-21). To Lange, Fechner's panpsychism - which he calls "pantheistic naturalism" - was an important contemporary example of how this conflation was still occurring in natural science (Lange 1866, ix).

As we have seen, du Bois-Reymond was perfectly aware of these implications that he considered as undesirable and unfruitful risks. In the second edition of his History of Materialism, Lange praised him for having challenged the German tendency to speculation, quoting more contemporary examples, such as "the identification of will and impulse to movement in Schopenhauer," the "cosmic ether" of Philipp Spiller, and the "sentient matter" of Friedrich Überweg. Lange focused on the case of Friedrich Zöllner, a physicist in Leipzig who had argued that since sensation is a "much more fundamental fact of observation than the mobility of matter" we are forced to consider it as "the most general property and condition of the comprehensibility of natural changes" (Zöllner 1872, 321). Later Zöllner would attempt to invoke the authority of Helmholtz, who had granted the possibility of a fourth spatial dimension, in support of his experimental investigation of spiritualism - one that included table-moving (Stromberg 1989).

These were not isolated and bizarre cases. Lange himself admitted that the limits of materialism and the epistemic precedence of psychic phenomena suggested this kind of conclusions. But he was not prepared to endorse such a "speculative" and unscientific view and eventually opted for a Kantian phenomenalism, or "materialism of the phenomenon," pledging ignorance about the "transcendent basis" of the world (Lange 1866, 323-4; 493, 496; 1875, II, 164-165, 398). Wilhelm Wundt preferred the opposite tack: he argued that materialism has the "immanent requirement" to decide whether to deny psychic phenomena or to endorse them as "original 
properties," thus turning into dualism or Spinozian monism (Wundt [1874] 1880, II, 444). Wundt declared his predilection for a "spiritualist" (or "idealist") metaphysics, arguing that psychical phenomena are "primitive facts," while matter is hypothetical, and suggesting that bodies may be conceived as "momentary minds" (ibid. 444, 451-8, 461). He also maintained that the development of organisms and the Darwinian struggle for survival presupposed psychical drives (ibid., 457-8). Thus, he overturned the leading theory of philosophical naturalism on the grounds of spiritualism.

Prominent scientists would explicitly oppose du Bois-Reymond's Ignorabimus striking similar notes. Ernst Haeckel (another student of Müller) and Karl von Nägeli defended the animation of atoms, proceeding - as Bois-Reymond replied $(1886,388,413 \mathrm{n} .8)$ - "in full coherence with the spirit of a false philosophy of nature." In the light of all these examples we can better understand du Bois-Reymond's agnosticism with respect to metaphysical hypotheses as a fundamental consequence of his epistemological perspective. In this regard, the problem of consciousness did not coincide with a "mystery" in the sense of an insoluble scientific problem, it was rather no scientific problem at all. Instead, it was an "enigma" whose solution lay beyond natural science. The ultimate sense of his lecture is that the scientist has to reject once and for all the traditional alternatives and frame his own view of the problem "inductively" - that is, by investigating the neural conditions of consciousness - without expecting to get to a valid answer to the problem of consciousness:

The more frankly the student of natural science acknowledges these appointed limits, and the more humbly he is reconciled to this ignorance, the more profoundly conscious is he of his right inductively to fashion his own views as to the relations between mind and matter, with perfect freedom, and untrammeled by myths, dogmas, or time-honored philosophies (LN, $126 / 30)$.

6. Let me now turn to the contemporary science of consciousness with its metaphysical revival. While du Bois-Reymond's recommended epistemic caution ("entia non sunt creanda sine necessitate" 1886, 388), many scientists and philosophers of today consider metaphysics as a relatively new and promising way that deserves more credit. This depends - I submit on the long denial of metaphysics in the Vienna Circle, which discouraged metaphysical investigations on the mind-body problem for decades. This background suggests the importance of reconsidering the Ignorabimus controversy and its tortuous historical connection to present philosophy. Du Bois-Reymond's position about science and epistemic "riddles" was turned by Carnap into a complete dismissal of the problem of consciousness as a specious and ill-posed metaphysical pseudo-problem (Carnap $1928 \$ \$ 166-169)$. Identity theorists of the 1950s, in turn, restated the problem: Herbert Feigl, e.g., commented on the hypothesis of an "autocerebroscope," which would allow the observation of one's own "cerebral nerve currents" in real time, arguing that the "synthetic" correlation of psychical and material phenomena could be empirically investigated after all and corroborate explanatory hypotheses, thus challenging du Bois-Reymond's Ignorabimus. Feigl saw "no plausible scientific theory anywhere in sight" to explain the psychophysical correlations, but he endorsed an "identity theory" about "raw feels" as intrinsic properties of matter, thus opposing the empiricist anti-metaphysical interdiction (Feigl [1958] 1967, 62-63, 89, 105).

This renewed problem position coincided with the "fresh start" of contemporary philosophy of mind, which is generally considered to have begun in the 1950s with attempts to reconsider phenomenal consciousness, or raw feels, as a scientific problem, after its exclusion by Wittgenstein, logical empiricism and behaviorism. In turn, the contemporary problem of phenomenal consciousness is mostly the result of a critique of identity statements about conscious states 
and brain states. From this point of view it is remarkable that this new identity theory - at least in the version advocated in the United States by Herbert Feigl - is historically rooted in a tradition that (via Moritz Schlick and Alois Riehl) leads back to post-Kantian philosophy, that is, to the same context of emergence of the Ignorabimus. ${ }^{17}$

This does not mean that contemporary discussions can be considered as a re-play of old ones, if by "re-play" one means a repetition rather than a re-elaboration. Notwithstanding the analogy and historical dependence, contemporary philosophy and neuroscience have developed finer tools to assess the problem of consciousness. ${ }^{18}$ My question - formulated from the critical standpoint of the Ignorabimus - is whether contemporary neuroscience is in any better position to answer the metaphysical questions that Feigl and later philosophers of mind expected to be solved by the "neuroscience of the future."19

It is striking how neuroscientists have often revisited modern metaphysical alternatives in order to provide theoretical interpretations of their own models (Pecere 2015, 345-354; Pecere 2020, chap. 6). Francis Crick, Gerald Edelman, and Jean-Pierre Changeux have proposed different kinds of materialistic theories; Antonio Damasio, recognizing the insufficiency of psychophysical correlation, has revived a kind of Spinozism; and Giulio Tononi has developed Information Integration Theory by means of concepts of consciousness and anti-reductionism inspired by Descartes and Leibniz. To be sure, scientists tend to present their models and theories as independent from these metaphysical frameworks. On the contrary, a number of philosophers, while admitting the importance of these advances in neuroscience, have advocated the need to integrate scientific models with metaphysical elements. Today variants of Russellian monism, panpsychism, and dualism are once again on the philosophical agenda, and the way these views are defended bears striking similarities with the argumentative context that I have presented (e.g. see Chalmers, n. 1 above; Searle 2008; Strawson 2017). On the other hand, ingenious strategies to dismiss the problem of consciousness in purely functional (e.g. Dennett), conceptual (e.g. Tye) and even linguistic (e.g. Bennett and Hacker) terms are also being pursued. In this context, du Bois-Reymond's Ignorabimus presents the interesting case of how scientists can at the same time recognize the explanatory problem and wonder whether the endorsement of any metaphysical answer adds anything to its solution.

In order to illustrate this point, let me refer to a discussion raised by Gerald Edelman's pioneering attempt to develop a scientific theory of consciousness. Edelman's theory identified the neural correlate of consciousness with a variable "dynamic nucleus" of neurons. The hypothesis was motivated by a naturalistic and biological view which was inspired, among others, by John Searle (Edelman 1989, 49-52) and therefore would have met - at least in principle - the requirements of Searle's "biological naturalism." While recognizing that Edelman's theory is a "most accurate and profound attempt," Searle has argued that it still does not explain "how" neural mechanisms "cause" consciousness, so that "the mystery remains" (Searle 1997, 48-50). Edelman's reply to the kind of request made by Searle was that it was mistaken and ill-posed in that it did not recognize what a scientific theory of consciousness could provide:

It suffices to explain the bases of these distinctions - just as it suffices in physics to give an account of matter and energy, not why there is something rather than nothing. This our

\footnotetext{
${ }^{17}$ Feigl ([1958] 1967, 79-80, 84) quoted Schlick as his source and suggested that Schlick had been influenced by the monism (or "identity theory") of the neo-Kantian philosopher Alois Riehl. Schlick, in turn, would present his realistic monism as a kind of double-aspect theory inspired by Kant. This monistic reading of Kant was already in Lange's account of the problem of consciousness. A detailed reconstruction of this story exceeds the limits of this paper. See Heidelberger (2003) for a partial reconstruction.

${ }^{18}$ I thank David Chalmers for pressing me on this point in conversation.

${ }^{19} \mathrm{Feigl}([1958] 1967,75,83)$ cautiously remarked that he was thinking of "knowledge and devices that may be available a thousand years hence," and saw the solution coming in this far future: "3000 AD." His ideal was a perfect "microphysical account" of the brain in terms of "atomic and sub-atomic concepts."
} 
theory can do by pointing out the differences in neural structure and dynamics underlying different modalities and brain functions (Edelman 2004, 146; emphasis added).

This approach reproduces du Bois-Reymond's conception of scientific methodology as purely structural-dynamical with a dismissal of any further explanation. ${ }^{20}$

Similar dissatisfactions with contemporary models of the neural correlates of consciousness have been expressed by Chalmers (2010, 11, also regarding Crick's hypothesis) and Block (2009, 1111-2, regarding Tononi's theory). The disagreement expressed by this portion of the philosophical community - as it is remarked in a recent paper by Ned Block (2015) - regards in general the capacity of physical conditions of consciousness to provide a "ground" of subjective experience: the "ontological" thesis that only matter exists does not eliminate the "metaphysical" question of which is the "ground" of phenomenal experiences in different kinds of beings. Block maintains that, even if ontological materialism is true, metaphysical materialism could fail, for there could not be any physical explanation of phenomenal commonalities (Block 2015, 113-4). From this perspective, Block points out that the main research program of twentiethcentury materialism neglected the problem of ground, thus leaving open the possibility that "dualism, in an important sense, is true" (Block 2015, 133). This further example suits Chalmers' remark that materialism is "unstable" and can collapse into different metaphysical hypotheses.

Against this background, the historical reconsideration of the Ignorabimus poses a double challenge: first, is it possible that a philosophical or metaphysical explanation of consciousness will expand our knowledge with respect to what the detection of neural correlates can provide? Second, is it possible to establish the truth of a determinate explanation - such as a kind of materialism or panpsychism - with respect to the others? The burden of proof - more than one hundred years after du Bois-Reymond - still belongs to a future science of consciousness that denies the Ignorabimus.

Acknowledgments. The research for this paper was initiated at the Philosophy Department of New York University with the support of a Fulbright Research Scholarship. I thank Béatrice Longuenesse, David Chalmers, and two anonymous reviewers for insightful comments on previous versions of the paper.

\section{References}

Bayertz, Kurt, Myriam Gerhard, and Walter Jaeschke, eds. 2007. Weltanschauung, Philosophie und Naturwissenschaft im 19. Jahrhundert. Bd. 3. Der Ignorabimus-Streit. Hamburg: Meiner.

Bayertz, Kurt, Myriam Gerhard, and Walter Jaeschke, eds. 2012. Der Ignorabimus-Streit. Hamburg: Meiner.

Beiser, Friedrick. 2014. After Hegel: German Philosophy (1840-1900). Princeton NJ: Princeton University Press.

Block, Ned. 1995. "On a Confusion about a Function of Consciousness." Behavioral and Brain Sciences, 18: $227-287$.

Block, Ned. 2009. "Comparing the Major Theories of Consciousness." In The Cognitive Neurosciences, $4^{\text {th }}$ ed., edited by M. Gazzaniga, 1111-1122. Cambridge MA: The MIT Press.

Block, Ned. 2015. “The Canberra Plan Neglects Ground.” In Qualia and Mental Causation in a Physical World, edited by T. Horgan, M. Sabates, and D. Sosa, 105-133. Cambridge: Cambridge University Press.

Block, Ned, David Carmel, et al. 2014. "Consciousness Science: Real Progress and Lingering Misconceptions." Trends in Cognitive Science 18:56-57.

Carnap, Rudolf. 1928. Der logische Aufbau der Welt. Berlin: Weltkreis Verlag.

Cassirer, Ernst. 1956. Determinism and Indeterminism in Modern Physics: Historical and Systematic Studies of the Problem of Causality. Translated by O. T. Benfey. Yale University Press/Oxford University Press: New Haven/London.

Chalmers David J. 1996. The Conscious Mind. In Search of a Fundamental Theory. Oxford: Oxford University Press.

\footnotetext{
${ }^{20}$ Still Edelman's position did not entirely reproduce du Bois-Reymond's position, because he argued that once we will have understood its "mechanisms in more detail" consciousness will no longer be a "mystery" (Edelman 2003, 5524). On the contrary, as we have seen, du Bois-Reymond believed that the scientific explanation did not solve the metaphysical riddle.
} 
Chalmers David J. 2002. "Consciousness and Its Place in Nature." In Guide to the Philosophy of Mind, edited by S. Stich and T. Warfield, 247-272. Cambridge: Blackwell. Reprinted in David J. Chalmers, ed. Philosophy of Mind: Classical and Contemporary Readings. 2002. New York: Oxford University Press.

Chalmers David J. 2010. The Character of Consciousness. New York: Oxford University Press.

Chalmers David J. 2016. "Panpsychism and Panprotopsychism." In Panspychism. Contemporary Perspectives, ed. by. G. Bruntrup and L. Jaskolla. Oxford: Oxford University Press, 19-47.

Chalmers David J. 2019. "Idealism and the Mind-Body Problem." In The Routledge Handbook of Panpsychism. Abingdon: Routledge.

Chalmers David J. and Paolo Pecere. 2019. “Dialogo sulla coscienza.” Il Tascabile. 1/10/2019. https://www.iltascabile.com/ scienze/coscienza-chalmers/.

Clarke, Edwin, and L. Stephen Jacyna. 1987. Nineteenth-Century Origins of Neuroscientific Concepts, Oakland: University of California Press.

Cranefield, Paul. 1957. "The Organic Physics of 1847 and the Biophysics of Today.” J. Hist. Med. Allied. Sci. 12(4):407-423.

Dennett, Daniel. [1969] 1985. Content and Consciousness. $2^{\text {nd }}$ ed. London: Routledge and Kegan Paul.

Descartes, Renée. [1662] 1964-74. L’homme. In Oeuvres de Descartes. Edited by R. Adam, P. Tannery. Paris: Vrin.

Du Bois-Reymond, Emil. [1872] 1886 = LN). "Über die Grenzen des Naturerkennens." In Reden. vol. I, $105-140$. Leipzig: Veit.

Du Bois-Reymond, Emil. 1886. Reden, vol. 1. Leipzig: Veit.

Du Bois-Reymond, Emil. [1848] 1887. "Über die Lebenskraft." In Reden. vol. 2, 1-28 [partial reprint of the Preface to the Untersuchungen über thierische Elekticität]. Leipzig: Veit.

Edelman, Gerald. 1989. Remembered Present. A Biological Theory of Consciousness. New York: Basic Books.

Edelman, Gerald. 2003. Naturalizing Consciousness. A Theoretical Network. Pnas 100(9):5520-4.

Edelman, Gerald. 2004. Wider than the Sky. The Phenomenal Gift of Consciousness. New Haven: Yale University Press.

Feigl, Herbert. [1958] 1967. The "Mental"” and the "Physical." Minneapolis: University of Minnesota Press. $2^{\text {nd }}$ edition.

Finkelstein, Gabriel. 2013. Emil du Bois-Reymond. Neuroscience, Self, Society in Nineteenth-Century Germany. Cambridge MA: The MIT Press.

Freeman, Antony, ed. 2006. Consciousness and Its Place in Nature: Does Materialism Entail Panpsychism? Exeter: Imprint.

Friedman, Michael. 2013. Kant's Construction of Nature. A Reading of the Metaphysical Foundations of Natural Science. Oxford: Oxford University Press.

Gregory, Frederick. 1977. Scientific Materialism in Nineteenth Century Germany. Dordrecht: Reidel.

Güzeldere, Güven. 1997. “Approaching Consciousness.” In The Nature of Consciousness, edited by N. Block, O. Flanagan, and G. Güzeldere. Cambridge MA: The MIT Press.

Haeckel, Ernst. 1874. Antropogenie oder Entwickelungsgeschichte des Menschen. Leipzig: Engelmann.

Hagner, Michael. 2008. Homo cerebralis. Der Wandel vom Seelenorgan zm Gehirn. Frankfurt a.M.: Suhrkamp.

Hagner, Michael, and Bettina Wahrig-Schmidt (Hrsg.). 1992. Johannes Müller und die Philosophie. Berlin: Akademie Verlag.

Heidelberger, Michael. 2003. "The Mind-Body Problem in the Origin of Logical Empiricism: Herbert Feigl and Psychophysical Parallelism.” In Logical Empiricism: Historical and Contemporary Perspectives, edited by P. Parrini and W. Salmon, 232-262. Pittsburgh: Pittsburgh University Press.

Heidelberger, Michael. 2004. Nature from Within. Gustav Theodor Fechner and His Psychophysical Worldview. Pittsburgh: University of Pittsburgh Press.

Helmholtz, Hermann. [1847] 1882. “Über die Erhaltung der Kraft.” In Wissenschaftliche Abhandlungen, vol. 1. Leipzig: Barth.

Helmholtz, Hermann. [1862] 1884. “Über das Verhältnis der Naturwissenschaften zur Gesamtheit der Wissenschaften.” In Vorträge und Reden, vol. 1. Braunschweig: Vieweg.

Helmholtz, Hermann. 1867. Handbuch des physiologischen Opticks, Leipzig: Voss.

Helmholtz, Hermann. 1871. "Bishop Berkeley on the Metaphysics of Sensation.” In Collected Essays, vol. 6: 243-87. London: Macmillan \& Co.

Huxley, Thomas. [1866] 1872. Lessons on Elementary Physiology. London: MacMillan \& Co.

Kandel, Eric. 2012. The Age of Insight. New York: Random House.

Kant, Immanuel. 1781. Kritik der reinen Vernunft. Riga: Hartknoch.

Kant, Immanuel. 1783. Prolegomena zu einer jeden künftigen Metaphysik, die als Wissenschaft wird auftreten können. In Kant's gesammelte Schriften, hrsg. von der Preussischen Akademie der Wissenschaften, vol. 4: 253-383. De Gruyter: Berlin.

Kant, Immanuel. 1786. Metaphysische Anfangsgründe der Naturwissenchaft. In: Kant's gesammelte Schriften, hrsg. von der Preussischen Akademie der Wissenschaften, vol. 4: 465-565. De Gruyter: Berlin.

Kant, Immanuel. 1787. Kritik der reinen Vernunft, $2^{\text {nd }}$ ed. Riga: Hartknoch.

Kirk, Robert, and J.E. Roger Squires. 1974. “Zombies v. Materialists.” Proceedings of the Aristotelian Society, Supplementary Volumes 48:135-163.

Lange, Friedrich. [1866] 1873-5 Geschichte des Materialismus und Kritik seiner Bedeutung in der Gegenwart 2 vols. Iserlohn: J. Baedeker. 
Lange, Friedrich. 1968. Über Politik und Philosophie. Duisburg: Walter Braun.

Leibniz, Gottfried Wilhelm. [1714] 1932. Monadologie. In Die philosophischen Schriften. Edited by C.J. Gerhardt (Hrsg.). Leipzig: Lorentz.

Leibniz, Gottfried Wilhelm. 1923-. Saemtliche Schriften und Briefe. Edited by Deutsche Akademie der Wissenschaften zu Berlin. Berlin: Akademie Verlag.

Locke, John. [1689] 1975. An Essay Concerning Human Understanding. Oxford: Oxford University Press.

McGinn Colin. 1989. “Can We Solve the Mind-Body Problem?” Mind, New Series 98(391):349-366.

Papineau, David. 2004. Thinking about Consciousness. Oxford: Oxford University Press.

Pecere, Paolo. 2015. "La coscienza come problema scientifico tra filosofia e neuroscienze." In Il libro della natura, edited by Paolo Pecere, vol. 2, 317-370. Roma: Carocci.

Pecere, Paolo. 2016. "Monadology, Materialism and Newtonian Forces. The Turn in Kant's Theory of Matter." Quaestio. Yearbook for the History of Metaphysics 16:167-189.

Pecere, Paolo. 2018. "Lois, sensations et nerfs. Possibilité et limites de la neurophysiologie des fonctions mentales de Kant à Helmholtz." In Physique de l'esprit: empirisme, médecine et cerveau, edited by C. Cherici, J. C. Dupont, and C. T. Wolfe, 161-180. Paris: Hermann.

Pecere, Paolo. 2020 (forthcoming). Soul, Mind and Brain from Descartes to Neuroscience. A Critical History. New York: Springer.

Searle, John. 2008. “Dualism Revisited.” Journal of Physiology, Paris 101:169-178.

Strawson, Galen. 2017. "Physicalistic Panpsychism.” In The Blackwell Companion to Consciousness, edited by Susan Schneider and Max Velmans, chap. 27. doi: 10.1002/9781119132363.ch27.

Stromberg, Wayne H. 1989. "Helmholtz and Zoellner: Nineteenth-Century Empiricism, Spiritism, and the Theory of Space Perception." Journal of the History of the Behavioral Sciences 25:371-383.

Tennant, Neil. 2007. "Mind, Mathematics and the Ignorabimusstreit." British Journal for the History of Philosophy 15(4):745-73.

Thomas, Ernest Chester. 1925. History of Materialism and Criticism of Its Present Importance. London: Kegan Paul.

Tye, Michael. 1999. 'Phenomenal Consciousness: The Explanatory Gap as a Cognitive Illusion.' Mind 108(432):705-725.

Tye, Michael. 2016. "Qualia." The Stanford Encyclopedia of Philosophy (Summer 2018 Edition), Edward N. Zalta (ed.), URL https://plato.stanford.edu/archives/sum2018/entries/qualia/.

Tyndall John. 1871. Fragments of Science. New York: Appleton \& Co.

Wundt, Wilhelm. [1874] 1880. Grundzüge der physiologischen Psychologie, 2 vols. 2. völlig umgearbeitete Auflage. Leipzig: Engelmann.

Paolo Pecere is assistant professor of "History of philosophy" and "History of philosophical and scientific thought" at the University of Roma Tre. His research deals with connections among philosophy and natural sciences from the seventeenth century to today, with a particular focus on the Kantian and the neo-Kantian traditions.

Cite this article: Pecere, Paolo. 2020. "Reconsidering the Ignorabimus: Du Bois-Reymond and the Hard Problem of Consciousness," Science in Context 33:1-18. doi:10.1017/S0269889720000095 